\title{
Students' Perceptions of the Barriers to and Benefits From Service-Learning
}

\author{
Neena A. Xavier \\ Brenau University \\ Peter A. Jones \\ University of Alabama at Birmingham
}

With the increased use of service-learning (SL) experiences across disciplines, researchers have considered challenges and benefits for various stakeholders to the use of SL as a pedagogical strategy in the classroom. Primarily, the challenges have been framed from the faculty's perspective, and the benefits measured have been for undergraduate students. We address the gap in the literature by examining student perceptions of both barriers and benefits in a graduate program. Our results indicate that perceptions of benefits and barriers vary by a few student characteristics, but after participating in the SL experience, all students rated both benefits and barriers as less likely. From these results, we offer recommendations to improve SL experiences, especially at the graduate level.

Keywords: service-learning, graduate, healthcare, barriers, benefits

\section{INTRODUCTION}

Service-learning (SL) provides an opportunity for students to participate in practical activities that serve their communities while also reflecting on concepts and theories that are taught in their discipline (Ferrari \& Chapman, 2014). Academic programs across a multitude of fields have adopted SL components in their curricula (Bringle et al., 2013); and researchers have followed in measuring the implementation of and outcomes associated with SL (Salam et al., 2019).

Regarding implementation, previous work has mainly focused on implementation challenges that instructors faced, giving less attention to student perceptions of barriers to SL (Peters, 2011; Burke \& Bush, 2013; Toporek \& Worthington, 2014; Schoenherr, 2015). Likewise, researchers who measured outcomes associated with SL typically concentrated on academic benefits and critical thinking (Celio et al., 2011; Yorio \& Ye, 2012; Rutti et al., 2016; Asghar \& Rowe, 2017). Increasingly, the focus has shifted to benefits external to the classroom, like civic engagement, professional development, or teamwork (Foronda \& Belknap 2012; Marshall et al., 2015).

To address these gaps, we explore student perceptions of the barriers created by and benefits gained from SL. These perceptions should inform the implementation of SL projects and build on the emerging literature that examines its broader benefits (Marshall et al., 2015; Salam et al., 2019). Informed by Puri et al. (2013), we also consider whether student perceptions of barriers and benefits change after participating in an SL project. Specifically, our research questions are 1) Do student perceptions of barriers and benefits 
change after they participate in an SL activity; and 2) How are student demographics associated with the change in perceptions?

We examine these questions with evidence from an SL project completed by students in the clinical medicine courses in a Physician Assistant (PA), master's level program. While SL has been frequently used in health sciences and nursing (Salam et al., 2019), it is far less common in other professional programs. Similar to other master's programs but unlike medical school, PA programs have a shorter time frame for the practical application of skills. SL experiences enhance the curriculum by providing more opportunities for skill-building and real-world use, all while benefiting the community (Krumwiede et al., 2015).

Despite our focus on a master's level program, our results should be externally valid and relevant for all types of students. Undergraduates, for example, also often balance a course schedule with classes from a variety of disciplines, all while managing work and extracurricular activities. SL presents a challenge especially when it is not coordinated with other class demands. Graduate and professional students may also have work demands and are more likely to face family and childcare constraints or distance learning challenges, all of which become more difficult to manage when students have to participate in SL. In addition, the benefits of SL may be less direct or more delayed. For instance, an SL experience may help build a student's resume, but depending on how close to graduating a student may be, this benefit could take years to realize.

\section{LITERATURE REVIEW}

\section{Implementation of and Outcomes From SL Experiences}

Although there are a variety of definitions for SL in the literature, for the purposes of this study SL is defined as "a form of experiential education in which students engage in activities and that address human needs, together with structured opportunities for reflection designed to achieve desired learning outcomes" (Jacoby $1^{\text {st }}$ edition, 2015, p. 1-2). The various definitions of SL all contain similar elements including the need for critical reflection to improve learning and professional growth, alignment with specific learning outcomes to promote critical thinking and innovative problem-solving, and reciprocity to ensure that community partners define their own needs and create sustained, meaningful partnerships with mutual beneficiaries.

Salam et al. (2019) provides a robust review of service learning in higher education. In this review, the authors note several challenges to implementation, including managing the relationships among students, instructors, and community members (Toporek \& Worthington, 2014). Burke and Bush (2013) highlighted the coordination challenges of SL for instructors specifically; for example, timing of off-campus trips and scheduling transportation were an issue in using SL experiences in college classrooms. Peters (2011) highlighted the added effort required to prepare the experiences, and Schoenherr (2015) discussed the difficulties in connecting the SL experience to course learning objectives. Notably, Salam et al. (2017) did note a student's family obligation as a potential implementation challenge, but extant research has largely overlooked this facet of the SL experience.

Previous research has also assessed the potential benefits of SL for students, faculty, and community members. Comparatively, researchers have focused more on the benefits for students than potential barriers students might face, but most of these studies drew their empirical samples from undergraduate students. Again, Salam et al. (2019) systematic review includes many of these benefits, which reflect both the short and long term benefits for students who participate in an SL project.

Understanding both the barriers and benefits can help improve implementation, especially given that student perceptions change after undertaking a well-designed SL experience. Clevenger (2011) showed that student competencies increased after an SL project, and Wilson et al. (2020) highlighted how student motivation can change after they have participated in an SL experience. Poorly designed SL experiences can have the opposite effect. Foronda and Belknap (2012) detail an SL experience for Associate Degree Nursing (ADN) students and revealed themes of perceived powerlessness, being overwhelmed, and egocentrism after participating in SL. 


\section{SL in Healthcare Education}

As our sample is drawn from a cohort of students in a PA master's program, we also highlight some particular challenges within this field that SL activities can address. Broadly, the debate between timebased education and competency-based education has intensified, and master's level programs throughout the country are faced with the challenge to find methods of accurately assessing certain competencies that are necessary for graduating compassionate and competent providers to care for patients from a diverse background. In PA education specifically, recognizing and addressing health care disparities and providing culturally intelligent healthcare are considered core competencies (Force 2019). These two different competencies are also included in the updated standards released by their accrediting body (ARC-PA 2020). $\mathrm{SL}$ is an active learning strategy that is poised to provide educators the opportunity to assess and develop these competencies for future PAs.

Similar to PA education, there are many allied health professions such as clinical laboratory science, pharmacy, physical therapy, occupational therapy, etc. that do not have a mandatory residency component after graduation. Thus, hands-on training and real-world field experiences with timely, structured feedback included early-on in the didactic curriculum can serve as an essential method for students to analyze and/or restructure the conceptual frame through which they process information and provide patient interactions. $\mathrm{SL}$ is an experiential learning strategy that may provide such hands-on training.

\section{METHODS}

\section{Participants}

We observed one cohort of 80 students who participated in an SL experience during their second and third semesters of a five semester PA program. Designed based on Kolb's Experiential Learning Model, the SL program utilized an established interprofessional, student-run wellness screening clinic at the Firehouse Shelter, a male homeless shelter in Birmingham, Alabama. Students were primarily white (86.75 percent), female (71.25 percent), and had an average age of 26.

Specifically, master's level PA students staff a wellness screening clinic in teams of four students at the Firehouse Shelter. Patients access a variety of screening services, and based on the results of screening, PA students develop a medical management plan and refer patients to the appropriate available care providers. Other professional school students, including healthcare management, clinical laboratory science, occupational therapy, physical therapy, and optometry are present at the clinic as well to provide screening services within their scope of practice.

We deliberately incorporated this screening clinic as a mandatory SL component in their clinical medicine courses of the PA curriculum. The syllabi of these courses included instructional objectives that addressed recognizing and addressing health disparities as well as utilizing cultural intelligence in medical decision-making. All students staffed the clinic and completed a critical reflection assignment aligned with an instructional objective from their didactic course according to SL best practice (Jacoby $1^{\text {st }}$ edition, 2015).

\section{Survey Design and Procedure}

Data for this study was collected using a 46-question online survey that students completed through the university learning management system, Canvas. Students completed a pre- and post-questionnaire that included questions about their perceptions of community service, the patient population which they served, and the benefits and barriers of an SL course (IRB-300002754).

For this paper, we focus on a subset of twelve questions that asked how students perceived the benefits and barriers of an SL course. Specifically, students were presented with six statements about potential barriers and six statements about potential benefits. Then, they were asked to rate how much they were likely or unlikely to experience the barrier or benefit. There were seven response options, including "Extremely unlikely," "Moderately unlikely," "Slightly unlikely," "Neither likely nor unlikely", "Slightly likely," "Moderately likely," and "Extremely likely."

Because some students elected not to have their pre- or post-surveys used for research or did not provide complete data, we have a sub-sample of respondents for which we were able to match pre- and post-survey 
responses. First, we consider the potential bias of our sample selection. In Table 1, we compare the presurvey sample, post-survey sample, and the matched sample. Compared to the pre-survey sample, the matched sample is 1.1 years older, on average, and more likely to be white and female.

TABLE 1

COMPRAISON OF PRE-SURVEY, POST-SURVEY, AND MATCHED SAMPLES

\begin{tabular}{lccc}
\hline & Pre-survey & Post-survey & Matched sample \\
\hline $\begin{array}{l}\text { Respondents } \\
\text { Age }\end{array}$ & 80 & 71 & 61 \\
& 25.9 & 26.7 & 27.0 \\
Race & $(22 \mathrm{~min}, 38 \mathrm{max})$ & $(23 \mathrm{~min}, 38 \mathrm{max})$ & $(23 \mathrm{~min}, 38 \mathrm{max})$ \\
$\quad$ White & $69(86.75 \%)$ & $62(87.3 \%)$ & $54(88.5 \%)$ \\
$\quad$ Non-white & $11(13.25 \%)$ & $9(12.7 \%)$ & $7(11.5 \%)$ \\
Gender & & & \\
$\quad$ Female & $57(71.25 \%)$ & $54(76.1 \%)$ & $44(72.1 \%)$ \\
$\quad$ Male & $23(28.75 \%)$ & $17(23.9 \%)$ & $17(27.9 \%)$ \\
\hline
\end{tabular}

\section{Empirical Strategy}

With this paper, we empirically address two research questions. With our first research question, we ask whether student perceptions of barriers and benefits change after they participate in an SL activity. To address this question, we first present student responses across the twelve questionnaire items for both the pre- and post-surveys. To examine whether student perceptions change, we then use paired T-tests to determine whether there was a significant difference between students' pre- and post-responses.

For our second research question, we ask whether and how the changes in perceived benefits and barriers differed across students. With this question, we can understand if the potential change in perceptions were different in magnitude for various subgroups of students. For example, might older students perceive barriers to be less likely after participating in the SL project?

In addressing this second question, we can also explore whether pre- and post-perceptions for the benefits and barriers varied across student characteristics. In line with Carlisle et al. (2020), we generate a barrier index by summing student responses to the six questions about potential barriers to SL. We create a benefit index with the same procedure. As well, we construct these indices for both pre- and postquestionnaires, giving us four indices in total. By construction, these indices can range from 6 to 42 and represent a student's cumulative perception of the potential barriers and benefits created by participating in an SL activity. For both barriers and benefits, we subtract the pre-index from the post index to observe the change in perceptions. Table 2 shows the descriptive statistics for our four indices, as well as the difference between the pre- and post-values of each index.

TABLE 2

COMPARISON OF PRE-SURVEY AND POST-SURVEY BENEFITS AND BARRIERS INDICES

\begin{tabular}{lrrrr}
\hline & Mean & Std. Dev. & Min & Max \\
\hline Pre-survey & & & & \\
Benefits index & 38.426 & 3.658 & 27 & 42 \\
Barriers index & 23.082 & 6.761 & 9 & 37 \\
Post-survey & & & & \\
Benefits index & 36.770 & 4.876 & 23 & 42 \\
Barriers index & 19.934 & 7.922 & 6 & 39 \\
\hline
\end{tabular}


We use each of these indices as dependent variables in an OLS regression model. In these models, we control for age, gender, race, and a student's previous experiences with SL and volunteering. All of these variables were self-reported by the students, and the descriptive statistics for age, race, and gender were presented in Column 3 of Table 1. Of the 61 students, 43 students (70.49 percent) reported a previous community service experience. Also, 19 students (31.15 percent) reported never volunteering; 33 (54.10 percent) reported volunteering 1-4 times per year; and 9 (14.75 percent) reported volunteering monthly or more. An important note about our sample: 54 (88.52 percent) were white, one was Hispanic (1.64 percent), four were Asian (6.56 percent), and two were African-American (3.28 percent). Given the small numbers of minority students, we create a non-white subgroup for comparison purposes.

\section{RESULTS}

Table 3 presents the results from the pre-questionnaire for the twelve questions about barriers and benefits. The same response options were used for both barriers and benefits, so higher mean responses for barriers indicate that students consider service learning to be a bigger barrier (e.g. they would have less time), and high mean responses for benefits reflect more optimistic student perceptions.

On the pre-survey, students considered many of the barriers to be "Moderately unlikely" or "Slightly unlikely," on average. They did expect to have less time for schoolwork or free time, however. Before going through the SL project, students expected that all of the benefits were "Moderately likely" or "Extremely likely." On the post-survey, students considered all barriers to be "Moderately unlikely" or "Slightly unlikely," on average, and they rate all of the benefits to be "Moderately likely" or "Extremely likely."

TABLE 3

\section{DESCRIPTIVE STATISTICS FOR RESPONSES TO PRE- AND POST-QUESTIONNAIRES}

\begin{tabular}{|c|c|c|c|c|}
\hline & Mean & $\begin{array}{l}\text { Std. } \\
\text { Dev. }\end{array}$ & Min & Max \\
\hline \multicolumn{5}{|l|}{ Pre- questionnaire } \\
\hline \multicolumn{5}{|l|}{ Barriers } \\
\hline I would have less time for my schoolwork. & 4.951 & 1.371 & 1 & 7 \\
\hline $\begin{array}{l}\text { I would have forgone the opportunity to make money in } \\
\text { a paid position. }\end{array}$ & 2.820 & 1.727 & 1 & 7 \\
\hline I would have less energy. & 3.344 & 1.662 & 1 & 6 \\
\hline I would have less time to work. & 3.557 & 1.803 & 1 & 7 \\
\hline I would have less free time. & 4.557 & 1.467 & 1 & 7 \\
\hline I would have less time to spend with my family. & 3.852 & 1.579 & 1 & 7 \\
\hline \multicolumn{5}{|l|}{ Benefits } \\
\hline $\begin{array}{l}\text { I would be contributing to the betterment of the } \\
\text { community. }\end{array}$ & 6.623 & 0.553 & 5 & 7 \\
\hline $\begin{array}{l}\text { I would experience personal satisfaction knowing that I } \\
\text { am helping others. }\end{array}$ & 6.705 & 0.558 & 5 & 7 \\
\hline $\begin{array}{l}\text { I would be meeting other people who enjoy community } \\
\text { service. }\end{array}$ & 6.443 & 0.847 & 3 & 7 \\
\hline I would be developing new skills. & 6.393 & 0.936 & 4 & 7 \\
\hline $\begin{array}{l}\text { I would make valuable contacts for my professional } \\
\text { career. }\end{array}$ & 5.902 & 1.207 & 3 & 7 \\
\hline I would gain valuable experience for my resume. & 6.361 & 0.895 & 3 & 7 \\
\hline
\end{tabular}




\begin{tabular}{|c|c|c|c|c|}
\hline \multicolumn{5}{|l|}{ Post questionnaire } \\
\hline \multicolumn{5}{|l|}{$\underline{\text { Barriers }}$} \\
\hline I would have less time for my schoolwork. & 3.820 & 1.784 & 1 & 7 \\
\hline $\begin{array}{l}\text { I would have forgone the opportunity to make money in } \\
\text { a paid position. }\end{array}$ & 2.721 & 1.675 & 1 & 6 \\
\hline I would have less energy. & 2.820 & 1.466 & 1 & 6 \\
\hline I would have less time to work. & 3.361 & 1.592 & 1 & 7 \\
\hline I would have less free time. & 3.918 & 1.725 & 1 & 7 \\
\hline I would have less time to spend with my family. & 3.295 & 1.811 & 1 & 7 \\
\hline \multicolumn{5}{|l|}{ Benefits } \\
\hline $\begin{array}{l}\text { I would be contributing to the betterment of the } \\
\text { community. }\end{array}$ & 6.443 & 0.764 & 4 & 7 \\
\hline $\begin{array}{l}\text { I would experience personal satisfaction knowing that I } \\
\text { am helping others. }\end{array}$ & 6.426 & 0.763 & 4 & 7 \\
\hline $\begin{array}{l}\text { I would be meeting other people who enjoy community } \\
\text { service. }\end{array}$ & 6.262 & 1.094 & 2 & 7 \\
\hline I would be developing new skills. & 6.016 & 1.147 & 3 & 7 \\
\hline $\begin{array}{l}\text { I would make valuable contacts for my professional } \\
\text { career. }\end{array}$ & 5.639 & 1.291 & 2 & 7 \\
\hline I would gain valuable experience for my resume. & 5.984 & 1.176 & 2 & 7 \\
\hline
\end{tabular}

\section{Paired T-Test Results}

Next, we consider the differences in our pre- and post-survey responses with a paired T-test and present those results in Table 4. We find statistically significant differences for all but one of the questions about barriers and for all of the questions about benefits. Specifically, students rated both barriers and benefits to be likely after they participated in the SL project. The magnitudes of these differences were larger for barriers, on average, and the largest drop was associated with barriers that were of most concern on the presurvey.

TABLE 4

DIFFERENCES IN PERCEPTIONS BEFORE AND AFTER SL EXPERIENCE

\begin{tabular}{|c|c|c|c|c|}
\hline \multirow[b]{2}{*}{ Barriers } & \multirow[t]{2}{*}{$\begin{array}{l}\text { Pre-survey } \\
\text { (mean) }\end{array}$} & \multirow[t]{2}{*}{$\begin{array}{c}\text { Post-survey } \\
\text { (mean) }\end{array}$} & \multicolumn{2}{|c|}{ Difference } \\
\hline & & & & \\
\hline I would have less time for my schoolwork. & 4.951 & 3.820 & -1.131 & $* * *$ \\
\hline $\begin{array}{l}\text { I would have forgone the opportunity to make } \\
\text { money in a paid position. }\end{array}$ & 2.820 & 2.721 & -0.098 & \\
\hline I would have less energy. & 3.344 & 2.820 & -0.525 & $* * *$ \\
\hline I would have less time to work. & 3.557 & 3.361 & -0.197 & \\
\hline I would have less free time. & 4.557 & 3.918 & -0.639 & $* * *$ \\
\hline I would have less time to spend with my family. & 3.852 & 3.295 & -0.557 & $* *$ \\
\hline
\end{tabular}




\begin{tabular}{llll}
\hline $\begin{array}{l}\text { Benefits } \\
\text { I would be contributing to the betterment of the } \\
\text { community. }\end{array}$ & 6.623 & 6.443 & $-0.180 * *$ \\
$\begin{array}{l}\text { I would experience personal satisfaction knowing that I } \\
\text { am helping others. }\end{array}$ & 6.705 & 6.426 & $-0.279 * * *$ \\
$\begin{array}{l}\text { I would be meeting other people who enjoy community } \\
\text { service. }\end{array}$ & 6.443 & 6.262 & $-0.180 * *$ \\
$\begin{array}{l}\text { I would be developing new skills. } \\
\text { I would make valuable contacts for my professional }\end{array}$ & 6.393 & 6.016 & $-0.377 * * *$ \\
career. & 5.902 & 5.639 & $-0.262 * *$ \\
I would gain valuable experience for my resume. & 6.361 & 5.984 & $-0.377 * * *$ \\
\hline
\end{tabular}

$* * * \mathrm{p}<0.01, * * \mathrm{p}<0.05, * \mathrm{p}<0.1$

\section{Regression Results}

Table 5 presents the results from our regression where we modeled the association between our constructed benefits and barriers indices with various student characteristics. With this empirical estimation, we are measuring whether there were differences in perceptions of SL across different student groups, ceteris paribus.

Our results indicate that few observable student characteristics were associated with perceptions of benefits or barriers, before or after participating in the SL project. Of note, females rated barriers 4.32 points lower than males before participating in the SL project. Students who reported previous volunteer experience rated barriers 4.13 points lower before participating and benefits 3.57 points higher after participating.

TABLE 5

ASSOCIATION BETWEEN PERCEPTIONS OF BENEFITS AND BARRIERS WITH STUDENT CHARACTERISTICS

\begin{tabular}{|c|c|c|c|c|}
\hline VARIABLES & $\begin{array}{l}\text { Benefits } \\
\text { (pre) }\end{array}$ & $\begin{array}{l}\text { Benefits } \\
\text { (post) }\end{array}$ & $\begin{array}{l}\text { Barriers } \\
\text { (pre) }\end{array}$ & $\begin{array}{c}\text { Barriers } \\
\text { (post) }\end{array}$ \\
\hline Age & $\begin{array}{l}-0.158 \\
(0.154)\end{array}$ & $\begin{array}{l}-0.142 \\
(0.197)\end{array}$ & $\begin{array}{c}0.217 \\
(0.260)\end{array}$ & $\begin{array}{l}-0.166 \\
(0.327)\end{array}$ \\
\hline Gender $($ Male $=0$, Female $=1)$ & $\begin{array}{c}0.451 \\
(1.070)\end{array}$ & $\begin{array}{c}0.475 \\
(1.374)\end{array}$ & $\begin{array}{l}-4.319 * * \\
(1.808)\end{array}$ & $\begin{array}{l}-3.366 \\
(2.277)\end{array}$ \\
\hline Non-white, compared to white & $\begin{array}{c}0.315 \\
(0.762)\end{array}$ & $\begin{array}{c}0.261 \\
(0.979)\end{array}$ & $\begin{array}{l}-0.789 \\
(1.288)\end{array}$ & $\begin{array}{c}0.290 \\
(1.622)\end{array}$ \\
\hline Previous community service experience (pre) & $\begin{array}{l}1.066 \\
(1.091)\end{array}$ & $\begin{array}{c}0.432 \\
(1.402)\end{array}$ & $\begin{array}{l}0.178 \\
(1.844)\end{array}$ & $\begin{array}{l}-3.503 \\
(2.323)\end{array}$ \\
\hline $\begin{array}{l}\text { If volunteer, how often? } \\
\text { Compared to never volunteering }\end{array}$ & & & & \\
\hline $1-4$ times per year & $\begin{array}{c}1.089 \\
(1.083)\end{array}$ & $\begin{array}{l}3.568^{* *} \\
(1.391)\end{array}$ & $\begin{array}{c}-4.130 * * \\
(1.830)\end{array}$ & $\begin{array}{l}-3.689 \\
(2.304)\end{array}$ \\
\hline Monthly or more & $\begin{array}{c}0.595 \\
(1.527)\end{array}$ & $\begin{array}{l}3.539^{*} \\
(1.961)\end{array}$ & $\begin{array}{c}-6.574 * * \\
(2.580)\end{array}$ & $\begin{array}{l}-3.018 \\
(3.250)\end{array}$ \\
\hline Constant & $\begin{array}{l}40.728 * * * \\
(4.571)\end{array}$ & $\begin{array}{l}37.323 * * * \\
(5.872)\end{array}$ & $\begin{array}{l}23.781 * * * \\
(7.725)\end{array}$ & $\begin{array}{l}31.555^{* * *} \\
(9.729)\end{array}$ \\
\hline Observations & 61 & 61 & 61 & 61 \\
\hline R-squared & 0.082 & 0.148 & 0.233 & 0.114 \\
\hline
\end{tabular}

Standard errors in parentheses

$* * * \mathrm{p}<0.01,{ }^{* *} \mathrm{p}<0.05,{ }^{*} \mathrm{p}<0.1$ 
Next, Table 6 displays results from our regression that models the association between changes in our constructed benefits and barriers indices with various student attributes. Since we have already established in Tables 2 and 4 that students rated both benefits and barriers as less likely after participating in the servicelearning experience, the results presented in Table 6 indicate whether the magnitude of this change was different across students of different ages, genders, races, and previous community service and volunteer experience.

All of our coefficients were statistically and practically insignificant, suggesting that the SL project had the same effect across all students in changing perceptions. Compared to students who did not volunteer, students who reported volunteering 1-4 times per year had a 2.48 point higher change in their perception of benefits, but the standard errors around this estimate are too large to draw any substantive inferential conclusion.

TABLE 6

ASSOCIATION BETWEEN CHANGES IN PERCEPTIONS OF BENEFITS AND BARRIERS WITH STUDENT CHARACTERISTICS

\begin{tabular}{lcc}
\hline \multirow{2}{*}{ VARIABLES } & \multicolumn{2}{c}{ Change in } \\
Age & Benefits & Barriers \\
Gender (Male =, Female =1) & 0.016 & -0.384 \\
& $(0.202)$ & $(0.349)$ \\
Non-white, compared to white & 0.024 & 0.953 \\
& $(1.410)$ & $(2.433)$ \\
Previous community service experience (pre) & -0.054 & 1.079 \\
& $(1.004)$ & $(1.733)$ \\
& -0.634 & -3.681 \\
If volunteer, how often? & $(1.438)$ & $(2.482)$ \\
$\quad$ Compared to never volunteering & & \\
1-4 times per year & & \\
$\quad$ Monthly or more & & \\
& & \\
Constant & $2.479 *$ & 0.441 \\
& $(1.427)$ & $(2.462)$ \\
Observations & 2.944 & 3.556 \\
R-squared & $(2.012)$ & $(3.472)$ \\
S
\end{tabular}

Standard errors in parentheses

$* * * \mathrm{p}<0.01, * * \mathrm{p}<0.05, * \mathrm{p}<0.1$

\section{DISCUSSION}

SL has been increasingly implemented across a variety of disciplines and academic programs, and while a subset of research has considered student perceptions, this article extends the literature by examining student perceptions of both barriers and benefits. Specifically, we considered whether participating in an SL project changed perceptions of benefits and barriers and whether observable student characteristics were associated with perceptions and changes in perceptions. Since our sample was drawn from a cohort of PA students, the results from our estimations are directly relevant to other graduate programs, especially in the 
allied health fields. However, they could also be generalizable to a multitude of undergraduate programs across a variety of disciplines.

Our results indicate that after participating in the SL experience, student perceptions of both the benefits and barriers decreased. Considering barriers, the largest decreases occurred for barriers the students had ranked as most likely to happen on a pre-survey. Student perceptions of benefits also decreased, though the magnitudes of decrease was smaller, on average, than the decreases for barriers. As we previously described, the SL experience involved only one shift in the clinic, so students may not have had enough exposure to recognize the potential benefits of SL. Alternatively, many of the benefits in our survey are indirect or longer term. For example, students may not recognize they are contributing to the betterment of the community until later in their professional careers.

We also explored the association between student characteristics and their reported perceptions of SL. Female students and those who had previous volunteer experience were more likely to rate benefits as higher and barriers as lower. Other student characteristics were unrelated to their perceptions; and we found no evidence that changes in perceptions were different for our various subgroups.

As mentioned, SL is a high impact learning strategy that can help students gain a deeper understanding of and connection with the theories and concepts taught in the classroom. Given the potential benefits, we provide the following recommendations so that programs can plan and develop strategies for effective implementation of SL.

First, given that student perceptions of barriers decreased after participating in the SL experience, it is important to include SL experiences early in a student's college or curricular experience. Lower stakes SL experiences allow students to better understand the process, including what is required of them. Second, as professors introduce SL activities, it is important to provide students with information regarding time commitments and how the experience fits within the course and compared to other class activities. Students may be less likely to view an SL experience as a barrier if they understand it involves less of a time commitment than studying for an exam or writing a paper, for example.

Third, programs should devise a strategy to have dedicated time in the program set aside for participating in their SL experience. With this planning, students have the opportunity to focus on and engage with the particular activity, especially in the context of allied health professions that do not include significant cross discipline course work. Furthermore, we recommend structured critical reflection assignments strategically due around other major graded assessments such as exams or research papers to improve the effort and energy students spend on exploring their conceptual frameworks.

Finally, while students in our sample rate potential benefits as likely to occur, these benefits were perceived as less likely after the students completed the SL project. Faculty that use SL should directly discuss the benefits to introduce the SL experience and reinforce the professional development opportunities afterwards. For instance, faculty may implement a discussion group for students to reflect on and describe their enhancement of cultural competencies or their ability to recognize and address biases in the health care system that result in healthcare disparities. An alternate strategy is having more direct reflection assignments that ask the student to consider times when they positively impacted a community or person or given thought to the personal satisfaction they felt during the activity in serving others. By asking the students to directly give consideration to these benefits, they are more likely to crystalize in their minds and lead to positive, sustainable outcomes.

\section{Limitations and Future Directions}

Several limitations and strengths of this study should be considered when interpreting the results. One strength of this study is the sample size. In general, allied health programs have relatively smaller cohorts, so over 80 students in a cohort can be considered relatively large for most allied health programs. Statistically, however, the sample size provides little power and yielded large standards errors, which means our estimates should be considered conservative. With a larger sample size, perhaps more of our covariates would have been statistically significant. Also, our data were self-reported, which could result in biased results through a respondent's selective memory or over/under estimation of the impact from the SL experience. 
Findings from this study highlight potential future lines of research including measuring trends over time as more experience with SL will inform curricular changes and improvement in reflection assignments. In addition, assessing faculty perceptions of barriers and benefits to utilizing SL can be an important focus for future studies that could inform institutional policies to facilitate successful implementation strategies. A strength of this study is its use of an allied health profession that, up to this point, has been underreported in SL literature. It is also clear that understanding student perceptions of the barriers and benefits is critical for the successful implementation of SL across all disciplines.

\section{ACKNOWLEDGEMENT}

Funding for this research was received through a grant from the Engaged Scholarship Consortium.

\section{REFERENCES}

Accreditation Review Commission on Education for the Physician Assistant (ARC-PA). (2020, September). Accreditation Standards for Physician Assistant Education (5th edition).

Asghar, M., \& Rowe, N. (2017). Reciprocity and critical reflection as the key to social justice in service learning: A case study. Innovations in Education and Teaching International, 54(2), 117-125. https://doi.org/10.1080/14703297.2016.1273788

Bringle, R.G., Clayton, P.H., \& Hatcher, J.A. (2013). Research on service learning: An introduction. In P.H. Clayton, R.G. Bringle, \& J.A. Hatcher (Eds.), Research on service learning: Conceptual frameworks and assessment (Vol. 2A, pp. 3-25). Sterling, VA: Stylus.

Burke, A.S., \& Bush, M.D. (2013). Service learning and criminal justice: An exploratory study of student perceptions. Educational Review, 65(1), 56-69. https://doi.org/10.1080/00131911.2011.638138

Celio, C.I., Durlak, J., \& Dymnicki, A. (2011). A meta-analysis of the impact of SL on students. Journal of Experiential Education, 34(2), 164-181. https://doi.org/10.5193/JEE34.2.164

Clevenger, K.M. (2011). Effects of a formal service-learning program on baccalaureate nursing student's perception of their level of cultural competence (Doctoral dissertation, ProQuest Information \& Learning).

Force PCCT. (2019). Core Competencies for New Physician Assistant Graduates, pp. 1-20.

Foronda, C.L., \& Belknap, R.A. (2012). Short of transformation: American ADN students' thoughts, feelings, and experiences of studying abroad in a low-income country. International Journal of Nursing Education Scholarship, 9(1), 1-16.

Jacoby, B. (2015). SL Essentials: Questions, Answers, and Lessons Learned (First Edition). Jossey-Bass: A Wiley Brant.

Krumwiede, K.A., Van Gelderen, S.A., \& Krumwiede, N.K. (2015). Academic-hospital partnership: Conducting a community health needs assessment as a service learning project. Public Health Nursing, 32(4), 359-367. https://doi.org/10.1111/phn.12159

Marshall, J.H., Lawrence, E.C., Williams, L.J., \& Peugh, J. (2015). Mentoring as SL: The relationship between perceived peer support and outcomes for college women mentors Studies in Educational Evaluation, 47, 38-46. https://doi.org/10.1016/j.stued uc.2015.07.001

Peters, K.A. (2011). Including service learning in the undergraduate communication sciences and disorders curriculum: Benefits, challenges, and strategies for success. American Journal of Audiology, 20(2), S181. https://doi.org/10.1044/1059-0889(2011/10-0031)

Puri, A., Kaddoura, M., \& Dominick, C. (2013). Student perception of travel SL experience in Morocco. Journal of Dental Hygiene, 87(4), 235-243.

Rutti, R.M., LaBonte, J., Helms, M.M., Hervani, A.A., \& Sarkarat, S. (2016). The service learning projects: Stakeholder benefits and potential class topics. Education + Training, 58(4), 422-438. https://doi.org/10.1108/ET-06-2015-0050

Salam, M., Iskandar, D.N.A., Ibrahim, D.H.A., \& Farooq, M.S. (2019). Service learning in higher education: A systematic literature review. Asia Pacific Education Review, 20(4), 573-593. 
Salam, M., Iskandar, D.N.F.A., \& Ibrahim, D.H.A. (2017). Service-learning support for academic learning and skills development. Journal of Telecommunication, Electronic and Computer Engineering (JTEC), 9(2-10), 111-117.

Schoenherr, T. (2015). SL in supply chain management: Benefits, challenges and best practices. Decision Sciences Journal of Innovative Education, 13(1), 45-70. https://doi.org/10.1111/dsji12052

Toporek, R.L., \& Worthington, R.L. (2014). Integrating service-learning and difficult dialogues pedagogy to advance social justice training. The Counseling Psychologist, 42(7), 919-945.

Wilson, R., Látková, P., Yoshino, A., \& Sheffield, E. (2020). Changes in Volunteerism Perception: Results from an International Service Learning Case Study. SCHOLE: A Journal of Leisure Studies and Recreation Education, pp. 1-11.

Yorio, P.L., \& Ye, F. (2012). A meta-analysis on the effects of Service-learning on the social, personal, and cognitive outcomes of learning. Academy of Management Learning \& Education, 11(1), 927. https://doi.org/10.5465/amle.2010.007 